\title{
The Relationship of Transformational Leadership, Personality and Job Satisfaction to Organizational Citizenship Behavior (OCB)
}

\author{
${ }^{1}$ Dedi Supriadi, ${ }^{2}$ Soewarto Hardhienata, ${ }^{3}$ Rita Retnowati \\ ${ }^{1,2,3}$ Post Graduate Program, Universitas Pakuan Bogor, Indonesia
}

\begin{abstract}
The study aims to examine the influence of transformational leadership, personality and job satisfaction on teachers' organizational citizenship behavior (OCB). The variables of transformational leadership, personality and job satisfaction were treated as independent variables while the dependent variable is teachers' organizational citizenship behavior (OCB). The study was conducted on proportionally selected 198 lecturers of public senior high schools in the city of Bekasi, West Java, Indonesia. Using mix method, sequential explanatory design is applied where quantitative come first. The study both quantitatively and qualitatively reveals that there is a positive significant relationship among variables under the following distribution of coefficient of correlation: transformational leadership to teachers' organizational citizenship behavior $=0.777$, personality to teachers' organizational citizenship behavior $=0.916$, job satisfaction to teachers' organizational citizenship behavior $=0.852$ and when tested together it produces coefficient of correlation $=0.921$ and coefficient of determination $=0.847$ indicating the existence of other $15.3 \%$ variables not including in the model affecting organizational citizenship behavior in public senior high schools' working environment.
\end{abstract}

Keywords: Transformational Leadership, Personality, Job Satisfaction, OCB

\section{INTRODUCTION}

OCB is a positive action of people in the organization reflected in the form of willingness to knowingly and voluntarily to work extra time without any reward. OCB behavior of an individual's voluntary action is able to make a positive contribution to the organization. When performed in the organization, this behavior will enhance organizational effectiveness.

OCB of teachers will give a good impact on the schools, among others:(a) improving the performance of fellow teachers, (b) improving the performance of school principals, (c) saving the utilization of school resources, (d) being an effective means of coordinating the activities of the group work, (e) increasing the ability of schools to attract and to retain teaching staff and academic staff (f) improving school performance stability, and $(\mathrm{g})$ enhancing the organization's ability to adapt to changes in the school environment.

Initial survey on teachers' OCB conducted in the city of Bekasi generates the data below:

a) $60 \%$ of teachers are still expecting the reward in aiding the friends in organization.

b) $50 \%$ will help friends to provide information, consultation or guidance

c) $60 \%$ of teachers do not want to give positive feedback in meetings at the school.

d) $30 \%$ of teachers do not always obey the rules of the organization optimally.

e) $70 \%$ of teachers did not participate in the external activities that are bringing the good name of the school.

Based on the background and the results of the identification of the problem, the formulation of the problem is

1. Does transformational leadership positively affect teachers' organizational citizenship behavior?

2. Does personality positively affect teachers' organizational citizenship behavior ?

3. Does job satisfaction positively affect teachers' organizational citizenship behavior? 


\section{LITERATURE REVIEW}

Bernard M. Bass and Ronald E. Riggio (2006) defines transformational leadership as behavior which can stimulate and inspire followers to achieve results in the process of developing leadership skills, vision and goals given organization, to challenge itself to innovate, solve problems, and develop the ability of the leadership to subordinates through guiding, mentoring, ,challenging and supporting. "Transformational leaders, on the other hand, are then those who stimulate and inspire followers both in achieving extraordinary outcomes and developing their own leadership capacity".

Yukl (2006) stated that transformational leadership is the behavior of a leader who is able to call on his followers moral values in their efforts to raise awareness of ethical issues and mobilize energy and resources to reform institutions. Factors associated with the above definition are: 1) communicating the vision, 2) expressive, 3) a risk taker and sacrificed himself, 4) communicating high expectations, 5) consistent behavior vision, 6) managing the respect of subordinates against leadership, 7) establishing the existence of a group or organization, 8) empowering subordinates.

Based on the theories mentioned above, it can be synthesized that transformational leadership is the behavior of a leader who can inspire subordinates (teachers) to commit to the vision of the school, communicating, motivating, directing, empowering subordinates, to be a model, developing the potential of subordinates as well as a new perspective in solving the problem. The dimensions and indicators are : 1) the influence of the ideal toward subordinates, 2) the inspiration that motivates, 3 ) intellectual stimulation, 4) treatment of subordinates, 5) communication skills, 6) the giver of challenge and support.

This study used the five-factor model of personality, frequently referred to as thebig five to represent normal range personality (Digman, 1990). The big five provides awell-accepted taxonomy that enhances understanding of the relation between personality constructs and important organizational criteria. The construct labels and representative traits of the big five are:(1) extraversion (sociable, talkative, active, and ambitious);(2) agreeableness (sympathetic, warm, kind, cooperative);(3) conscientious (dependable, organized, and persistent);(4) emotional stability (calm, unemotional, secure, and not angry); and (5) openness to experience (imaginative, cultured, broad minded, and flexible). As the introduction and general acceptance of the five-factor model also known as the big fiv research examining the link between personality and work behavior has intensified. The big five dimensions have been replicated in an impressive series of studies across countries and cultures and remain fairly stable over time (Rajiani, 2012).

Rue and Byars (2007) defines job satisfaction as an employee's general attitude towards work. This can be affected by factors such as working conditions, pay and benefits, employee attitudes towards the organisation, supervision of the work, the age and health. That mindset can be negative or positive depending on the mindset of the employees toward the main components of job satisfaction. Rue and Byars give us the understanding that job satisfaction does not come naturally for granted; but many factors that cause an employee be satisfied. Robins and Judge (2012) defines that job satisfaction is evaluative statement either for pleasure or unpleasure toward individual objects or events. Discontent is essentially a person's assessment of the work. Many factors affect employee satisfaction, including: salaries, allowances, achievement, autonomy, recognition, communication, working conditions, the importance of work, coworkers, professionalism, organisational climate, interpersonal relationships, working for a prominent institutions, supervisory support, positive activity, job security, workplace flexibility, working in a cohesive team and genetic factors. Low work satisfaction is associated with the laborious tasks such as documentation, repetition task, the tension in the role expectations, ambitious role, conflicted role, feeling overloaded, increasing the need to be available for overtime, a co-worker relationships, personal factors and organisational factors.

OCB is one of the main topics that get practitioners and researchers attention and interests. Many studies have been done to identify the factors that enhance OCB. Organizational Citizenship Behavior was first defined by Organs (1997) as individual behavior that is discretionary, not directly or explicitly recognized by the formal reward system, and that is in the aggregate promotes the effective functioning of the organization. According to Mcshane \& Glinow (2008), one of the defining characteristics of engaged employees is that they perform beyond task performance standard or expectations. They will go the extra step, or maybe even the extra mile, to support the interest of organizations. Furthermore, OCB is defined by many experts e.q. Colquitt et.al (2009) who basically 
has the same meaning as voluntary employee activities that may or may not be a reward but that contribute to the organization by improving the overall quality of the setting in which work takes place.

Based on the literature review the following hypothesis is formulated:

1. Transformational leadership positively affects teachers' organizational citizenship behavior.

2. Personality positively affects teachers' organizational citizenship behavior.

3. Job satisfaction positively affects teachers' organizational citizenship behavior.

\section{Data Collection}

This study applies mix method with direct observation to the field aimed at analyzing the phenomenon occur when the research took place then confirm the finding by using direct depth interview. This way, writers apply Sequential Explanatory Mixed Methods. Descriptive statistics and quantitative analysis are used for finding initial solution to the problem encountered. The population of this study were 394 public senior high school teachers located in Bogor, West Java Indonesia. Using Slovin's formula to proportionally determine the sample, the number of 198 samples are obtained

Techniques of data collection in this study is in the form of questionnaire. The normality assumption is prerequisites to proceed to further test. Analysis is conducted with multiple linear regression and hypothesis testing is performed at a significance level of 0.05 .

\section{RESUlt AND DISCUSSION}

The teachers of listed organisations were asked to participate in the survey by responding their opinions for four different measures in Transformational Leadership, Personality and Job Satisfaction to Organizational Citizenship Behavior. The normality is performed with Lilliefors test. Data are normally distributed as the value of each variable is not exceeding the critical value for Lilliefors test. The Lilliefors normality test values for Transformational Leadership, Personality Job Satisfaction to Organizational Citizenship Behavior are $0.041,0.049$ and 0.058 respectively below the critical value of 0.093 for $\mathrm{n}=198$.

\subsection{The Effect of Transformational Leadership to Organizational Citizenship Behavior}

Hypothesis testing confirms that transformational leadership positively affects organizational citizenship behavior with correlation coefficient value of 0.777 and the coefficient of determination $=$ 0.664. This means that $66.4 \%$ of organizational citizenship behavior is determined by transformational leadership, while the other $36.6 \%$ is contributed by other variables. Similarly, result of qualitative research interviews, observation and documentation confirms the tendency of the relationship between transformational leadership with organizational citizenship behavior. This finding strengthens the quantitative research hypothesis results testing that there is a positive significant relationship between transformational leadership and organizational citizenship behavior.

This is in line with the findings of research conducted by Lian and Tui (2012) and Jahangir et al, (2004). Lia and Tui were doing research on service companies of manufacturers, mining and construction. Research results showed that transformational leadership style has a positive correlation to the OCB of subordinates. Jahangir research proves that transformational leadership style has a strong influence on the employee's willingness to engage in OCB.

\subsection{The Effect of Personality to Organizational Citizenship Behavior}

Hypothesis testing confirms that personality positively affects organizational citizenship behavior with correlation coefficient value of 0.916 and the coefficient of determination $=0.839$. This means that $83.9 \%$ of organizational citizenship behavior is determined by personality, while the other 16.1 $\%$ is contributed by other variables. Similarly, result of qualitative research interviews, observation and documentation confirms the tendency of the relationship between personality with organizational citizenship behavior. This finding strengthens the quantitative research hypothesis results testing that there is a positive significant relationship between personality and organizational citizenship behavior.

Some of the results of previous studies have shown that personality is positively related to OCB, one of them carried out by Malik et.al (2012). The analysis proves that there is a positive and significant 
relationship between personality with OCB with coefficient correlation value of $r=0.508$ and proved that personality positively affects on OCB. Thus results of this study further support the results of previous studies about the positive influence of personality on OCB.

\subsection{The Effect of Job Satisfaction to Citizenship Behavior}

Hypothesis testing confirms that job satisfaction positively affects organizational citizenship behavior with correlation coefficient value of 0.852 and the coefficient of determination $=0.725$. This means that $72.5 \%$ of organizational citizenship behavior is determined by job satisfaction, while the other $27.5 \%$ is contributed by other variables. Similarly, result of qualitative research interviews, observation and documentation confirms the tendency of the relationship between job satisfaction with organizational citizenship behavior. This finding strengthens the quantitative research hypothesis results testing that there is a positive significant relationship between job satisfaction and organizational citizenship behavior.

This finding is consistent with the results of research conducted by Murphy et al. (2002) and Mohammad et al. (2011).Murphy found that job satisfaction has a significant and positive relationship on OCB. Mohammad et al (2011) also show that job satisfaction, both extrinsic and intrinsic are very important in predicting organizational citizenship behavior (OCB).

\subsection{Interaction of Transformational Leadership, Personality and Job Satisfaction to Organizational Citizenship Behavior}

When tested together, hypothesis testing results show that there is a significant relationship between Transformational Leadership, Personality and Job Satisfaction to Organizational Citizenship Behavior. The regression equation generated is $\hat{Y}=19,672+0,137 X_{1}+0,562 X_{2}+0,098 X_{3}$, with correlation of coefficient values $=0.921$ and the coefficient of determination $=0.847$. This means that $84.7 \%$ of organizational citizenship behavior is caused by variables of transformational leadership, personality and job satisfaction while $15.3 \%$ is contributed by other variables not included in the model. Result of qualitative research interviews, observation and documentation in the respective college also confirms the relationship among transformational leadership, personality and job satisfaction to organizational citizenship behavior. This finding strengthens the quantitative research hypothesis results testing that there is a positive significant relationship among those mentioned variables.

\section{CONClusion}

The findings reveal that there is a positive and significant direct effect between the transformational leadership, personality and job satisfaction to organizational citizenship behavior. Based on the initial design of the constellation between variables, the results showed that the contribution of transformational leadership to organizational citizenship behavior is $66.4 \%$, personality is $83.9 \%$, and job satisfaction is $72.5 \%$ indicating the highest individual contribution to the teachers' organizational citizenship behavior is personality. When combined together, contribution of the three variables reaches $84.7 \%$ indicating the contribution of other variables not included in the model to predict organizational citizenship behavior are only $15.3 \%$ confirming this model is of good-fit. Other researchers wishing to conduct similar studies may include other variables such as; teachers' professionalism, achievement motivation, work culture of teachers, teachers' resilience, creativity, work experience, training, management, decision-making techniques and so forth.

\section{REFERENCES}

Bernard M., Bass dan Ronald E. Riggio (2006).Transformational Leadership-2 ${ }^{\text {nd }}$ ed.New Jersey: Lawrence Erlbaum Associates.

Colquitt, J A, Jeffery A. Lepine \& Michael J. Wesson. Organizational Behavior:Improving Performance and Commitment in the Workplace. New York: McGraw-Hill, 2009.

Chatman, Jennifer A., David F. Caldwell, and Charles A. O'Reilly (1999). "Managerial personality and performance: A semi-idiographic approach." Journal of Research in Personality 33, no. 4 $.514-545$.

Digman, J.M. (1990) Personality structure: Emergence of the five-factor. Annual Review of Psychology 1: 417-440.

Jahangir, N., Akbar, M., and Haq, M. 2004. Organizational Citizenship Behaviors: Its Nature and Antecedents, BRAC University Journal, Vol I, No 2, pp. 75- 85. 
Lian, L.K., and Tui, L.G. 2012. Leadership Styles and Organizational Citizenship Behavior:The Mediating Effect of Subordinates' Competence and Downward Influence Tactics, Journal of Applied Business and Economics, Vol 13, No 2, pp. 59-96.

Malik, M. E., Ghafoor,M. M.,\&Iqba, H. K. (2012). Leadership and Personality Traits as Determinants of Organizational Citizenship Behaviour (OCB) in Banking Sector of Pakistan. World Applied Sciences Journal, 20(8), 1152-1158.

Mohammad, J., Habib, F. Q., \& Alias, M. A. (2011). Job satisfaction and organisational citizenship behaviour: An empirical study at higher learning institutions. Asian Academy of Management Journal, 16(2), 149-165.

Murphy, G., Athanasou, J., \& King, N. (2002). Job satisfaction and organizational citizenship behaviour: A study of Australian human-service professionals. Journal of Managerial Psychology, 17(4), 287-297.

Organ, Dennis W. Organizational Citizenship Behavior: It's Construct Clean-up Time. School of Business Indiana University, 1997.

Rajiani, Ismi (2012). "Applying Personality Traits to Predict Loyalty and Neglect among Employees of Bank Jatim Located in 10 Big Cities of East Java (Mc Crae's and Hofstede's Theories on effect of Culture to Personality Revisited)." Jurnal Aplikasi $\quad$ Manajemen 8, no.3, 2012, pp-617-623.

Robbins, S. P. \& T. A. Judge (2012). Organizational Behavior. New Jersey: Pearson Education,

Yukl, Gary (2010). Leadership in Organizations- $7^{\text {th }}$ ed.NewJersey: Pearson Education, Inc, Upper Saddle River. 